\title{
MENINJAU LOYALITAS NASABAH MELALUI CITRA MEREK DAN KUALITAS PELAYANAN AGEN BRILINK (Survey Pada Agen Brilink Bri Kantor Cabang Kemayoran)
}

\author{
Nurdinni Tilova \\ Program Studi Manajemen Fakultas Ekonomi Universitas Pamulang \\ Email: dosen02216@unpam.ac.id
}

\begin{abstract}
ABSTRAK
Tujuan dari riset ini merupakan mengumpulkan perspektif nasabah guna mengkaji loyalitas nasabah pada Agen Brilink BRI Kantor Cabang Kemayoran serta memperluas ikatan antara anggapan mereka terhadap citra merk serta mutu pelayanan mereka. Riset ini memakai ilustrasi nasabah pada Agen Brilink Cabang Kemayoran dengan jumlah responden 100. Tipe informasi yang digunakan merupakan informasi primer berbentuk angket serta informasi sekunder riset pustaka, Pengolahan informasi riset memakai analisis deskriptif serta analisis SEM dengan SmartPLS. Hasil dari riset ini melaporkan kalau variabel citra merk mempengaruhi positif serta signifikan terhadap variabel loyalitas nasabah, serta variabel mutu pelayanan pula mempengaruhi positif serta signifikan terhadap variabel loyalitas nasabah. Bersumber pada nilai RSquare buat variabel loyalitas nasabah merupakan 0, 685. Perolehan nilai tersebut menarangkan kalau presentase besarnya loyalitas nasabah bisa dipaparkan oleh citra merk serta mutu pelayanan sebesar $68 \%$.
\end{abstract}

Kata Kunci : Citra Merek, Kualitas Pelayanan, Loyalitas Nasabah.

\section{ABSTRACT}

The reason of this think about is to gather client viewpoints to survey client dependability to Brilink BRI Specialists at the Kemayoran Department Office and to broaden the relationship between their discernments of brand picture and their benefit quality. This think about employments a test of clients at the Brilink Specialist Kemayoran Department with a add up to of 100 respondents. The sort of information used is essential information within the frame of surveys and auxiliary information from writing thinks about, preparing investigate information utilizing expressive investigation and SEM investigation with SmartPLS. The comes about of this study state that the brand picture variable features a positive and critical impact on the client devotion variable, and the benefit quality variable moreover encompasses a positive and critical impact on the client devotion variable. Based on the RSquare esteem for the client devotion variable is 0.685 . Getting this esteem clarifies that the rate of client devotion can be clarified by brand picture and benefit quality by $68 \%$.

Keywords : Brand Image, Service Quality, Customer Loyalty.

\section{PENDAHULUAN}

\section{A. Latar Belakang Permasalahan}

Kemajuan dunia saat ini berjalan dengan cepat, yang membuat persaingan yang tak terhindarkan menjadi meningkat. Sehingga membuat dunia begitu terbuka, mengingat untuk jagat bisnis dan perbankan. Saat ini dunia keuangan di 
Jurnal Semarak,Vol.4,No.3,Oktober 2021, Hal (78-92)

Indonesia sedang memasuki masa persaingan yang sangat ketat. Pendakian bank-bank yang hadir di Indonesia dengan berbagai macam administrasi dan pilar yang menjadi pertimbangan masyarakat umum sangat berfluktuasi dalam dunia keuangan. Pendekatan yang berbeda untuk menarik klien baru menjadi klien standar atau menahan setiap klien sulit untuk setiap Bank. Klien adalah tulang punggung setiap bank untuk terus maju dan terus memanfaatkan layanan dan manfaat produk mereka. Oleh karena itu, sangat baik dapat diselesaikan dengan membuat pengembangan produk dan mengembangkan administrasi lebih lanjut.

Masih banyak masyarakat yang penasaran, menggunakan atau memperoleh administrasi perbankan dan administrasi moneter lainnya, antara lain karena mereka tinggal di daerah yang jauh dari kantor Bank atau ada biaya atau persyaratan yang merepotkan yang membuat pemerintah saat ini kuat dalam mengatur dan melaksanakan prosedur publik untuk mencapai keuangan inklusif. Keuangan inklusif. yang dimaksud adalah suatu keadaan di mana seluruh daerah pasti dapat menjangkau administrasi moneter dan memiliki budaya meningkatkan penggunaan administrasi moneter. Tata cara umum pelaksanaan penggabungan keuangan ini dilakukan oleh Otoritas Jasa Keuangan atau biasa disebut OJK, Perbankan, dan badan administrasi moneter lainnya. Salah satu proyek OJK adalah Laku Pandai, yang dibatasi sebagai Officeless Financial Services.

(https://www.ojk.go.id/id/Pages/Laku-

Pandai.aspx).

Dalam mendukung program ini, BRI sebagai salah satu pilihan masyarakat dalam mengelola rekening merupakan organisasi terbesar dan paling tak terbantahkan, memiliki media kecakapan moneter untuk masyarakat umum melalui organisasi Agen BRILink. BRILink merupakan perpanjangan tangan dari BRI dimana BRI bekerja sama dengan nasabah BRI sebagai tenaga ahli yang dapat melayani pertukaran perbankan untuk masyarakat umum secara terus menerus berbasis web dengan memanfaatkan fitur EDC miniATM BRI atau secara portable berbasis premis menggunakan Android dengan konsep sharing cost. Agen BRILink dapat melayani penukaran uang tunai, non tunai/T-Bank dan Mini Bank. Penukaran uang misalnya di bank seharihari adalah simpanan uang muka, toko dan tarik tunai, sedangkan T-Bank adalah barang elektronik cash berbasis pekerja yang diklaim oleh BRI yang menggunakan nomor ponsel terdaftar sebagai nomor rekod. Administrasi T-Bank dapat diakses di agen BRILink sehingga dapat dimanfaatkan oleh masyarakat pada umumnya sebagai "rekening" dana investasinya dan dapat diperoleh dengan pendaftaran sederhana tanpa melalui unit kerja. (https://bri.co.id/about -brilink)

Berdasarkan penelitian sebelumnya dari Yulia Larasati Putri dan Hardi Utomo tahun 2017 dengan judul "Pengaruh Kualitas Pelayanan Terhadap Loyalitas Pelanggan dengan Kepuasan sebagai Variabel Intervening (Studi Persepsi pada Klien Dian Comp Ambarawa)", menyatakan bahwa kualitas bantuan berpengaruh positif dedikasi klien secara fundamental pada tingkat kepentingan $(\mathrm{p}<0,01)$. Hal ini menunjukkan bahwa pembeli yang senang dengan produk atau layanan tertentu pada umumnya akan dapat setia pada produk atau layanan tersebut.

"Kondisi saat ini, banyaknya penawaran pesaing BRI yang memberikan keuntungan yang menjanjikan kepada nasabah, menjadi salah satu alasan relokasi nasabah BRI. Beberapa pesaing BRI misalnya telah menawarkan administrasi khusus untuk bursa perbankan, seperti 
Agen BNI46, Agen BTPN, Mitra BukaLapak, Agen Laku Pandai Mandiri, Payfazz, dan lain-lain yang wilayahnya fokus pada pasar miniatur yang sebenarnya merupakan pasar terbesar BRI" ( Susendra, 2018)

Tabel 1.1

Perbandingan Agen Branchless Banking

\begin{tabular}{|c|c|c|}
\hline $\begin{array}{c}\text { BRILINK } \\
\text { (BRI) }\end{array}$ & $\begin{array}{c}\text { AGEN } 46 \\
\text { (BNI) }\end{array}$ & $\begin{array}{c}\text { Layanan } \\
\text { Keuangan } \\
\text { Digital } \\
\text { (LKD } \\
\text { Mandiri) }\end{array}$ \\
\hline $\begin{array}{l}\text { - Transfer } \\
\text { - Setor } \\
\text { Tunai } \\
\text { - Tarik } \\
\text { Tunai } \\
\text { - Pembaya } \\
\text { ran PLN } \\
\text { - Pembaya } \\
\text { ran } \\
\text { PDAM } \\
\text { - Pembelia } \\
\text { n Pulsa } \\
\text { Listrik } \\
\text { dan } \\
\text { Telepon } \\
\text { - Pembaya } \\
\text { ran } \\
\text { Cicilan } \\
\text { - Top Up } \\
\text { BRIZZI }\end{array}$ & $\begin{array}{l}\text { - Transfer } \\
\text { - Setor } \\
\text { Tunai } \\
\text { - Tarik } \\
\text { Tunai } \\
\text { - Pembelia } \\
\text { n Pulsa } \\
\text { Listrik } \\
\text { dan } \\
\text { Telepon } \\
\text { - Pembaya } \\
\text { ran } \\
\text { Cicilan } \\
\text { - Isi } \\
\text { Ulang } \\
\text { Uang } \\
\text { Elektron } \\
\text { ik }\end{array}$ & $\begin{array}{l}\text { - Transfer } \\
\text { - Setor } \\
\text { Tunai } \\
\text { - Tarik } \\
\text { Tunai } \\
\text { - } \quad \text { Pembel } \\
\text { ian } \\
\text { Pulsa } \\
\text { Listrik } \\
\text { dan } \\
\text { Telepo } \\
\text { n } \\
\text { Isi } \\
\text { Ulang } \\
\text { Uang } \\
\text { Elektro } \\
\text { nik }\end{array}$ \\
\hline
\end{tabular}
2020

Sumber: Data Intern Perusahaan tahun

Tabel 1.2

Perbandingan Tarif Agen Branchless Banking

\begin{tabular}{|c|c|c|c|c|}
\hline $\begin{array}{l}\text { FITU } \\
\mathbf{R}\end{array}$ & $\begin{array}{l}\text { BRIL } \\
\text { INK } \\
\text { (BRI) }\end{array}$ & $\begin{array}{l}\text { FEE } \\
\text { AGE } \\
\mathrm{N}\end{array}$ & $\begin{array}{l}\text { AGE } \\
\text { N 46 } \\
\text { (BNI } \\
\text { ) }\end{array}$ & $\begin{array}{l}\text { FEE } \\
\text { AGE } \\
N\end{array}$ \\
\hline $\begin{array}{l}\text { Transfe } \\
\mathrm{r} \\
\text { Sesama }\end{array}$ & $\begin{array}{l}\text { Rp.3.0 } \\
00\end{array}$ & $\begin{array}{l}\text { Rp. } \\
1.500\end{array}$ & - & - \\
\hline
\end{tabular}

\begin{tabular}{|c|c|c|c|c|}
\hline $\begin{array}{l}\text { Transfe } \\
\text { r Antar } \\
\text { Bank }\end{array}$ & \begin{tabular}{|l|} 
Rp.15. \\
000 \\
dan \\
Rp.20. \\
000 \\
\end{tabular} & $\begin{array}{l}\text { Rp.6. } \\
000 \\
\text { Rp.8. } \\
500\end{array}$ & $\begin{array}{l}\text { Rp.6. } \\
500\end{array}$ & - \\
\hline $\begin{array}{l}\text { Pemba } \\
\text { yaran } \\
\text { PLN }\end{array}$ & \begin{tabular}{|l} 
Rp.30 \\
00
\end{tabular} & $\begin{array}{l}\text { Rp.1. } \\
350\end{array}$ & $\begin{array}{l}\text { Rp.3 } \\
000\end{array}$ & $\begin{array}{l}\text { Rp.1. } \\
750\end{array}$ \\
\hline
\end{tabular}

Sumber: Data Intern Perusahaan tahun 2020

Dan berikut data perolehan jumlah agen dan data transaksi selama tahun 2017 sampai tahun 2020 pada Agen BRILink BRI Cabang Kemayoran.

Tabel 1.3

Data Jumlah Agen dan Transaksi Agen BRILink dari tahun 2017-2020

\begin{tabular}{|c|c|c|c|c|}
\hline $\begin{array}{c}\text { N } \\
\text { o }\end{array}$ & $\begin{array}{c}\text { Tahu } \\
\mathbf{n}\end{array}$ & $\begin{array}{c}\text { Juml } \\
\text { ah } \\
\text { Agen }\end{array}$ & $\begin{array}{c}\text { Transa } \\
\text { ksi }\end{array}$ & $\begin{array}{c}\Delta \\
\text { Transa } \\
\text { ksi }\end{array}$ \\
\hline 1 & 2017 & 850 & 820.088 & - \\
\hline 2 & 2018 & 928 & $\begin{array}{c}1.423 .0 \\
76\end{array}$ & $\begin{array}{c}\uparrow \\
602.988\end{array}$ \\
\hline 3 & 2019 & 1.013 & $\begin{array}{c}1.497 .4 \\
15\end{array}$ & $\begin{array}{c}\uparrow \\
74.339\end{array}$ \\
\hline 4 & 2020 & 1.190 & $\begin{array}{c}1.412 .2 \\
21\end{array}$ & $\begin{array}{c}\downarrow \\
8.194\end{array}$ \\
\hline
\end{tabular}

Sumber: BRI Cabang Kemayoran

Berdasarkan data yang ditampilkan pada tabel diatas, nilai transaksi yang telah dilakukan nasabah melalui Agen Brilink setiap tahun hampir meningkat kecuali pada tahun 2020. Namun dilihat detail pertumbuhan transaksi tahun 2018 ke 2019 mengalami penurunan dibanding pertumbuhan transaksi tahun 2017 ke 2018 yaitu dari 820.088 menjadi 1.423.076, sehingga mengalami kenaikan sebesar 602.988 transaksi. Sedangkan pertumbuhan pada transaksi tahun 2018 ke 2019 yaitu dari sebesar 1.423.076 menjadi 1.497.415, sehingga mengalami kenaikan sedikit sebesar 74.339 transaksi. Kemudian mengalami penurunan kembali pada tahun 2020 sebesar 85.194. 
Bersumber pada perihal tersebut diatas, guna mengenali serta menguasai sepanjang mana loyalitas nasabah terhadap produk dan pelayanan pada pengguna BRILink maka penulis tertarik untuk membahas masalah tersebut dalam Penelitian yang berjudul "Meninjau Loyalitas Nasabah Melalui Citra Merek Dan Kualitas Pelayanan Agen Brilink Bri Kantor Cabang Kemayoran".

\section{B. Perumusan Masalah}

1. Bagaimana pengaruh citra merek terhadap loyalitas nasabah pada Agen BRILink BRI Kantor Cabang Kemayoran?

2. Bagaiama pengaruh kualitas pelayanan terhadap loyalitas nasabah pada Agen BRILink BRI Kantor Cabang Kemayoran?

3. Bagaimana pengaruh citra merek dan kualitas pelayanan terhadap loyalitas nasabah pada Agen BRILink BRI Kantor Cabang Kemayoran?

\section{KAJIAN PUSTAKA}

\section{A. Citra Merek}

Definisi citra merk menurut Sangadji dan Sopiah (2013:327) yaitu "Citra Merek (brand image) dapat dianggap sebagai jenis asosiasi yang muncul di benak konsumen ketika mengingat sebuah merek tertentu. Asosisasi tersebut secara sederhana dapat muncul dalam bentuk pemikiran atau citra tertentu yang dikaitkan dengan suatu merek, sama halnya ketika kita berpikir mengenai orang lain".

Menurut Kotler dan Keller (2016:330) menyatakan bahwa "Brand imagery describes the extrinsic properties of the product or service, including the ways in which the brand attempts to meet customers psychological or social needs". Yang dapat diartikan bahwa citra merek menggambarkan sifat ekstrinsik produk atau jasa, termasuk cara dimana merek berusaha memenuhi kebutuhan psikologis atau sosial pelanggan.

Sedangkan menurut Kotler dan Armstrong (2014:233) menyatakan bahwa citra merek adalah "The set of belief held about a particular brand is known as brand image". Yang artinya adalah sekumpulan keyakinan terhadap suatu merek disebut citra merek.

Menurut Kenneth dan Donald (2018:42) menyatakan bahwa "citra merek mencerminkan perasaan yang dimiliki konsumen dan bisnis tentang keseluruhan organisasi serta produk atau lini produk individu". Sedangkan menurut Schiffman dan Wischenblit (2015:133) menyatakan bahwa "citra merek adalah suatu gambaran yang berbeda yang dimiliki merek dalam benak konsumen".

Mengingat sebagian dari penilaian di atas, dapat diduga bahwa gambaran merek adalah wawasan tentang kepribadian pelanggan ketika mengingat merek tertentu pada suatu barang atau administrasi. Sesuai pendapat Aaker dan Biel dalam (Keller, 2012:239) Indikator yang digunakan untuk mengukur gambaran merek adalah sebagai berikut:

a) Citra Pembuat (Corporate Image)

Corporate Image adalah hubungan afiliasi yang telah dilihat oleh pembeli untuk suatu barang/administrasi yang mencakup ketenaran, kepercayaan, dan organisasi.

b) Citra Pemakai (User Image)

User Image adalah kumpulan afiliasi yang dilihat pembeli terhadap klien yang menggunakan produk atau 
layanan, termasuk klien itu sendiri, cara hidup, atau karakter, dan posisi masyarakat.

c) Citra Produk (Product Image)

$$
\text { Product Image adalah }
$$
sekelompok afiliasi yang dilihat oleh pelanggan untuk suatu produk, yang mencakup kredit produk, manfaat bagi pembeli, penggunaannya, dan sertifikasi.

\section{B. Kualitas Pelayanan}

"Pelayanan menurut Kamus

Besar Bahasa Indonesia (KKBI) adalah sebagai suatu usaha untuk membantu menyiapkan atau mengurus apa yang diperlukan orang lain". Sedangkan menurut Kotler dan Armstrong (2015:49) mengemukakan bahwa "kualitas pelayanan adalah keseluruhan ciri serta sifat dari suatu produk atau pelayanan yang berpengaruh pada kemampuannya untuk memuaskan kebutuhan yang dinyatakan atau tersirat".

"Pelayanan diberikan oleh suatu perusahaan untuk memenuhi kebutuhan dan keinginan konsumen demi tercapainya kepuasan pada konsumen itu sendiri. Oleh karena itu, definisi kualitas pelayanan dapat diartikan sebagai upaya pemenuhan kebutuhan dan keinginan konsumen serta ketepatan penyampaian dalam mengimbangi harapan konsumen" (Tjiptono, 2011:180).

Menurut Mauludin (2013:67) mengemukakan bahwa "kualitas pelayanan adalah seberapa jauh perbedaan antara kenyataan dan harapan pelanggan atas langganan yang mereka terima atau peroleh".
Menurut Tjiptono (2016:59)

menyatakan bahwa "kualitas pelayanan adalah tingkat keunggulan yang diharapkan dan pengendalian atas tingkat keunggulan tersebut untuk memenuhi keinginan pelanggan".

Bersumber pada bermacam komentar di atas hingga periset mengambil kesimpulan bahwasanya mutu pelayanan merupakan aktivitas yang dicoba oleh seseorang ataupun sekelompok orang guna penuhi kebutuhan serta kemauan konsumen sehingga konsumen merasa puas. Menurut Kotler \& Keller (2012:284), “Ada beberapa indikator yang mempengaruhi kualitas pelayanan, antara lain:

a) Bukti Fisik (Tangible), berkenaan dengan penampilan fisik fasilitas pelayanan, perlengkapan/peralatan yang digunakan dalam bekerja dan sumber daya manusia yang baik.

b) Reliability, berkaitan dengan kemampuan perusahaan dalam memberikan berbagai alternatif pilihan produk dan kecepatan pelayanan yang tepat secara akurat

c) Respon (Responsiveness), berkenaan dengan petugas yang dapat bertindak cekatan dan sigap dalam memberikan pelayanan terhadap kebutuhan nasabah dan memberikan solusi atas keluhan yang disampaikan kepada nasabah.

d) Assurance, berkaitan dengan kepastian pengiriman yang tepat dan mampu menjamin keamanan produk sampai ke tujuan. 
e) Empati, artinya perusahaan harus proaktif dalam mengkomunikasikan apa yang dibutuhkan pelanggan dan memahami serta mengutamakan materi prioritas yang harus diproduksi”.

\section{Loyalitas Nasabah}

Pengertian loyalitas nasabah menurut Oliver dalam Sangadji \& Sopiah (2013:104) menyatakan bahwa "loyalitas (loyalty) sebagai komitmen yang dipegang secara mendalam untuk membeli atau mendukung kembali produk atau jasa yang disukai di masa depan meski pengaruh situasi dan usaha pemasaran berpotensi menyebabkan pelanggan beralih".

Loyalitas Nasabah bersifat dinamis dan dapat berubah karena beberapa komponen, misalnya penyakit, perubahan tahapan dalam siklus kehidupan, keterbatasan waktu organisasi, perubahan gaji, standar abstrak (Tjiptono, 2012:84).

Menurut Kotler (2016:138) "loyalitas pelanggan adalah komitmen yang dipegang secara mendalam untuk membeli atau mendukung kembali produk atau jasa yang di sukai di masa depan, meski pengaruh situasi dan usaha pemasaran berpotensi menyebabkan pelanggan beralih".

Melihat perbedaan pendapat tersebut, ahli menyimpulkan bahwa pemikiran pengabdian klien dikatakan bahwa klien yang setia akan tetap setia menggunakan suatu barang atau jasa yang dia terima sesuai dengan kebutuhan dan keinginannya. Dia tidak akan berpindah ke merek lain kecuali jika merek tersebut memberikan lebih banyak keuntungan.
Sesuai Lupioadi (2013: 231) ada empat indikator loyalitas nasabah yang dapat dijelaskan sebagai berikut:

a) "melakukan pembelian secara teratur

Nasabah yang telah melakukan transaksi dengan perusahaan dan senang dengan apa yang mereka dapatkan akan membuat koneksi yang nyaman di antara nasabah dan apa yang mereka butuhkan, sehingga nasabag ini akan melakukan pembelian teratur.

b) Membeli antarlini produk dan jasa Nasabah tidak hanya mendapatkan satu jenis barang sebelum yang lain, tetapi mereka membeli embel-embel untuk barang-barang mereka, yang dapat ditambahkan klien ke barangbarang yang mereka beli.

c) Merekomendasikan produk kepada orang lain (refers other)

Nasabah yang selalu membahas produk kepada orang lain adalah sumber daya terbesar bagi perusahaan, di mana nasabah ini dan yang menyarankan akan secara konsisten membeli produk dan merek perusahaan, nasabah akan menjadi juru bicara yang dapat diterima untuk klien lain dan klien akan marah jika klien lain seseorang menyerang citra perusahaan. .

d) Menunjukkan kekebalan terhadap tarikan pesaing

Pelanggan tidak akan mengakui ada berbagai jenis produk, mereka yakin tentang produk yang mereka gunakan saat ini, dan sulit untuk beralih ke produk lain, mereka pikir produk yang digunakan saat ini benar-benar sesuai, dan banyak dari mereka telah percaya pada item yang sekarang digunakan.” 


\section{METODE PENELITIAN}

\section{A. Jenis dan Sumber Data}

"Jenis data dalam studi ini ialah data primer yang berasal dari jawaban responden atas kuesioner yang dibagikan . Data primer yakni data studi yang diperoleh secara langsung dari sumber asli" ( Indriantoro dan Supomo , 1999 dalam Yuteva , 2010 ). Sumber data berasal dari 100 responden nasabah agen Brilink Bri kantor cabang Kemayoran . Pengumpulan data menggunakan kuesioner online ( google form ) berupa catatan perkara yang nantinya hendak dijawab oleh responden sehabis itu hasilnya hendak diolah lagi oleh pengamat bersumber pada atmosfer maupun teori terpaut. Penyebaran dicoba secara langsung kepada responden yakni para nasabah agen Brilink BRI kantor cabang kemayoran.

\section{B. Metode Analisis Data}

$$
\text { "Pengolahan data studi }
$$
mengenakan analisis deskriptif dan analisis Structural Equation Modeling( SEM) dengan SmartPLS 3. 0. Analisis deskriptif ialah tata cara mengumpulkan data dengan tata cara data disusun sehabis itu diolah setelah itu analisis sehingga menghasilkan gambaran kasus yang ada"( Sugiyono, 2014). Studi ini, analisis deskriptif digunakan guna menganalisis gambaran citra merk, mutu pelayanan, serta loyalitas nasabah.

Untuk Ghozali( 2014) "SEM yakni tata cara analisis statistik multivariat buat menguji adanya suatu pengaruh secara langsung maupun tidak langsung yang lingkungan baik searah maupun tidak sehingga menghasilkan gambaran menyeluruh terjalin pada model. Analisis data mengenakan Partial Least Square( PLS) dan dibantu oleh aplikasi SmartPLS 3. 0 guna memudahkan studi. SEM dengan pendekatan PLS memiliki fleksibilitas besar buat pengamat guna menghubungkan antara teori dengan data"( Ghozali, 2014). Analisis SEM PLS dalam studi ini digunakan guna menganalisis pengaruh citra merk, mutu pelayanan, serta loyalitas nasabah.

\section{Definisi Operasional dan Pengukuran Variabel}

Variabel Dependen

a. Citra Merek (X1)

"Menurut Aaker dan Biel dalam

(Keller, 2012:239) indikator yang

digunakan untuk mengukur citra

merek (brand image) adalah sebagai berikut:

a) Citra Pembuat (Corporate Image)

b) Citra Pemakai (User Image)

c) Citra Produk (Product Image"

b. Kualitas Pelayanan (X2)

"Menurut Parasuraman, Valerie A. Zeithaml dan Berry dalam Fandy Tjiptono dan Gregorius Chandra (2011:198) mengemukakan bahwa terdapat lima dimensi layanan yang sering digunakan untuk mengukur kualitas pelayanan:

a) Reliability

b) Responsiveness

c) Assurance

d) Empathy

e) Tangibles"

\section{c. Loyalitas Nasabah (Y)}

"Menurut Lupioadi (2013:231) terdapat empat indikator loyalitas pelanggan yang dapat dijelaskan sebagai berikut:kualitas kerja,

a) Melakukan pembelian secara teratur

b) Membeli antarlini produk dan jasa

c) Merekomendasikan produk kepada orang lain

d) Menunjukkan kekebalan terhadap tarikan pesaing 


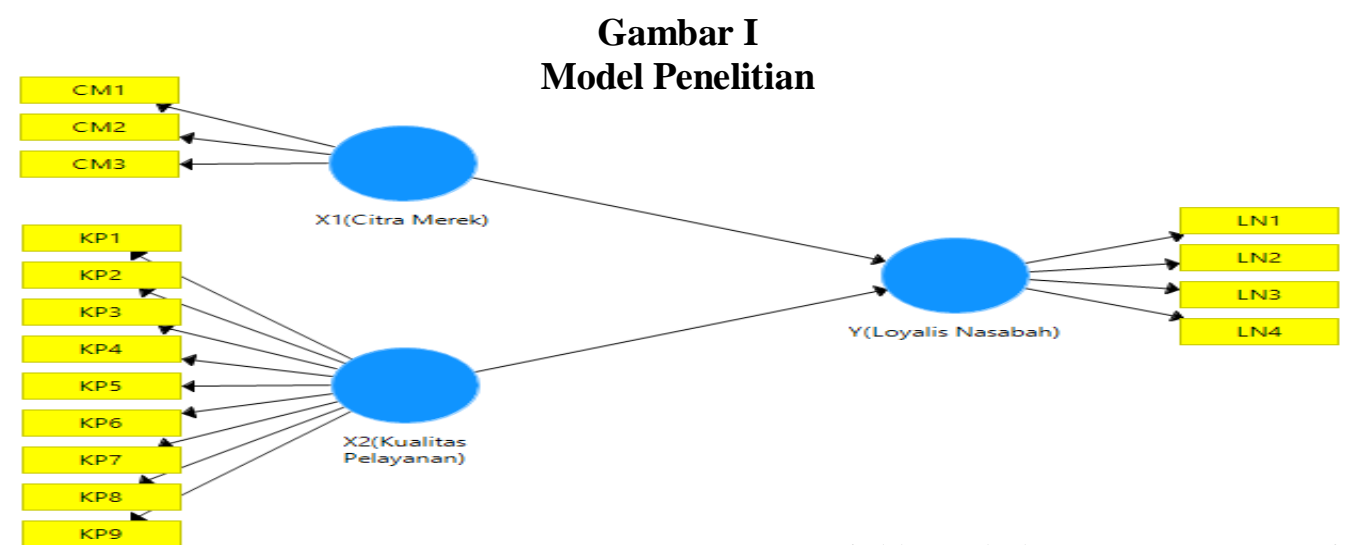

\section{HASIL PENELITIAN}

\section{A. Uji Instrument Data}

Uji instrumen yang digunakan dalam riset ini merupakan uji validitas serta reliabilitas didistribusikan kepada 100 nasabah BRILink BRI Cabang Kemayoran kemudian dianalisis validitas serta reliabilitasnya, Indikator reliabilitas dan validitas merupakan langkah awal untuk periksa dan jamin bahwa indikator terkait memiliki banyak hal umum yang ditangkap oleh konstruksi laten (Wong, 2019). Namun, setelah peneliti menilai validitas konvergen dengan memeriksa pemuatan eksternal dari setiap konstruksi laten, 2 dari 19 indikator dihapus karena eksternalnya pemuatan lebih rendah dari tingkat ambang batas 0,7 yang diusulkan oleh Rambut et al. (2014). Indikator yang tersisa adalah dipertahankan karena pemuatan eksternal mereka lebih tinggi dari ambang batas 0,7 .

B. Skema Model Partial Least Square (PLS)

Metode penelitian menggunakan Partial Least Squares (PLS) melalui Software SmartPLS 3. Model spesifikasi melibatkan model struktural dan pengukuran model. Sarstedt \& Cheah (2019) menjelaskan bahwa model struktural menunjukkan jalur antara konstruksi, sementara model pengukuran menunjukkan hubungan antara setiap konstruk dan indikatornya. Skema model program PLS yang diajukan:

\section{1). Evaluasi Outer Model}

Model outer dari riset ini menghasilkan variabel citra merek yang direfleksikan oleh 3 indikator, variabel kualitas pelayanan direfleksikan oleh 5 indikator, dan variabel loyalitas nasabah direfleksikan oleh 4 indikator. Tahapan dalam analisis SEM PLS "menurut Ghozali (2014) dalam mengembangkan model outer reflektif menggunakan 4 aturan, khususnya menguji validitas dan reabilitas dengan melihat pada Croanbach's Alpha, Composite Reliability, dan Average Variance Extracted (AVE) pada setiap variabel . Empat standar pengujian adalah sebagai berikut: 1) Convergent Validity: indikator dianggap solid jika nilai korelasi > 0,70 ".

"Factor loadings pada riset ini tidak semua indikator yang bernilai > 0,70 namun memiliki > $0,50 \mathrm{Hal}$ ini berarti bahwa penanda tersebut dapat dianggap dapat diandalkan. 2) Discriminant Validity: Suatu variabel dikatakan 
sah jika Average Variance Extracted (AVE) dari setiap faktor adalah > 0,50. 3) Composite Reliability: Suatu variabel dikatakan solid jika Composite Reliability setiap faktor > 0,70. 4) Croanbach's Alpha: Suatu variabel dikatakan dapat diandalkan jika Croanbach's Alpha pada setiap faktor > 0,70. Hasil tes adalah sebagai berikut: a. Convergent Validity, Untuk menguji Convergent
Validity, digunakan nilai faktor outer loading atau loading factor. Sebuah indikator diumumkan untuk memenuhi Convergent Validity dalam klasifikasi besar jika nilai outer loading atau loading factor $>$ 0,7"(Gozali:2014). Berikutnya adalah nilai penumpukan eksternal setiap idikator pada variabel eksplorasi:

Tabel 1

Outer Loadings

\begin{tabular}{cccc}
\hline Variabel & Indikator & $\begin{array}{c}\text { Outer } \\
\text { Loadings }\end{array}$ & Keterangan \\
\hline Citra Merek & $\mathrm{X} 1.1$ & 0,686 & Valid \\
(X1) & $\mathrm{X} 1.2$ & 0,801 & Valid \\
& $\mathrm{X} 1.3$ & 0,885 & Valid \\
\hline & $\mathrm{X} 2.1$ & 0,774 & Valid \\
& $\mathrm{X} 2.2$ & 0,740 & Valid \\
Kualitas & $\mathrm{X} 2.3$ & 0,639 & Valid \\
Pelayanan & $\mathrm{X} 2.4$ & 0,743 & Valid \\
(X2) & $\mathrm{X} 2.5$ & 0,675 & Valid \\
& $\mathrm{X} 2.6$ & 0,770 & Valid \\
& $\mathrm{X} 2.7$ & 0,791 & Valid \\
& $\mathrm{X} 2.8$ & 0,756 & Valid \\
$\mathrm{X} 2.9$ & 0,705 & Valid \\
\hline Loyalitas & $\mathrm{Y} .1$ & 0,669 & Valid \\
Nasabah & $\mathrm{Y} .2$ & 0,854 & Valid \\
(Y) & $\mathrm{Y} .3$ & 0,751 & Valid \\
& $\mathrm{Y} .4$ & 0,866 & Valid \\
\hline
\end{tabular}

Sumber : Data primer diolah, 2021

Bersumber pada sajian informasi pada tabel di atas, dikenal jika tiap- tiap variabel riset banyak yang meiliki outer loading sebesar 0,7 , namun nampak masih ada sebagian indikator yang mempunyai nilai outer loading\&lt; 0,7. Dimensi refleksif individual dikatakan besar bila berkorelasi lebih dari 0,70 dengan konstruk yang diukur, tetapi menurut
Ghozali (2006) "untuk penelitian tahap awal dari pengembangan skala pengukuran nilai loading 0,5 sampai 0,6 dianggap cukup memadai. Data di atas tidak menunjukkan adanya indikator variabel yang nilai outer loadingnya $<0,5$ sehingga semua indikator dinyatakan layak atau valid untuk digunakan analisis yang lebih lanjut". 


\section{2). Discriminant Validity}

Dalam penelitian ini peneliti menggunakan metode Average Variant Extracted (AVE) untuk mengetahui Discriminant Validity dalam setiap variabel. Agar bisa digunakan dan dikatakan valid setiap indikator dalam variabel memiliki kriteria sebesar $>0,5$.

Tabel 2

Discriminant Validity

\begin{tabular}{lcc}
\hline $\begin{array}{l}\text { Construct Reliability } \\
\text { and Validity }\end{array}$ & $\begin{array}{l}\text { Average Variance } \\
\text { extracted (AVE) }\end{array}$ & Keterangan \\
\hline CITRA MEREK & 0,632 & Valid \\
KUALITAS PELAYANAN & 0,539 & Valid \\
LOYALITAS NASABAH & 0,623 & Valid \\
\hline
\end{tabular}

Sumber : Data primer diolah, 2021

Berdasarkan sajian tabel di atas, dapat diketahui bahwa nilai AVE dari variabel Citra Merek > 0,5 atau sebesar 0,632, untuk nilai variabel Kualitas Pelayanan > 0,5 atau sebesar 0,539, dan untuk nilai variabel Loyalitas Nasabah > 0,5 atau sebesar 0,623. Hal ini menunjukkan bahwa setiap variabel telah memiliki discriminant validity yang baik.

\section{a). Composite Reliability}

Composite Reliability ialah bagian yang digunakan guna menguji nilai reliabilitas indikator- indikator variabel. Variabel bisa dikatakan penuhi Composite Reliability apabila nilai Composite Reliability dari tiap- tiap variabel nilainya 0,7 . Berikut ini merupakan nilai hasil dari Composite Reliability dari tiap- tiap variabel:

Gambar 2

Composite Reliability

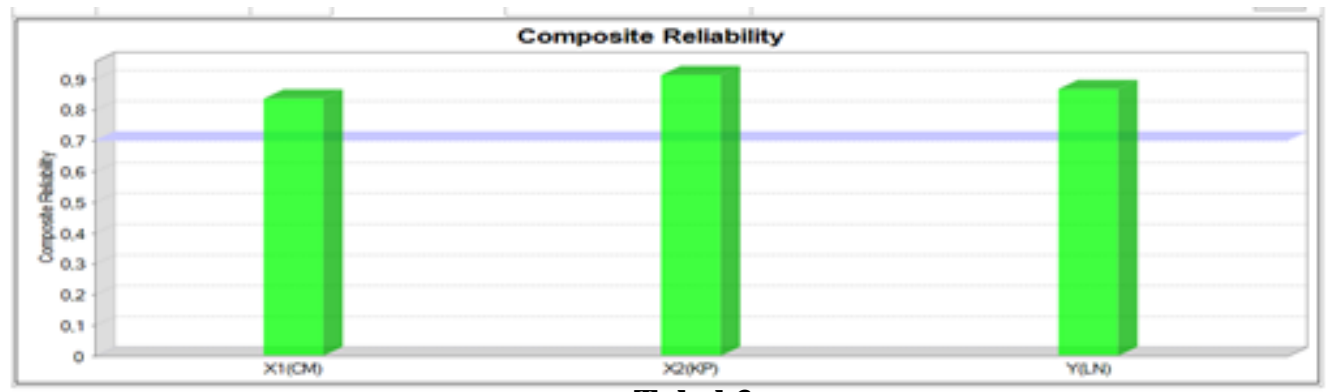

Tabel 3

Composite Reliability 


\begin{tabular}{lcc}
\hline \multicolumn{1}{c}{$\begin{array}{c}\text { Construct Reliability } \\
\text { and Validity }\end{array}$} & $\begin{array}{c}\text { Composite } \\
\text { Reliability }\end{array}$ & Keterangan \\
\hline CITRA MEREK & 0,836 & Reliable \\
KUALITAS PELAYANAN & 0,913 & Reliable \\
LOYALITAS NASABAH & 0,868 & Reliable \\
\hline
\end{tabular}

Sumber : Data primer diolah, 2021

Meninjau olah data pada tabel di atas, nilai Composite Reability dari variabel Citra merek > 0,7 yaitu sebesar 0,836 , kualitas pelayanan $>0,7$ yaitu sebesar 0,913 ,

dan Loyalitas Nasabah > 0,7 yaitu sebesar 0,868. Kemudian peneliti meninjau olah data nilai Composite Reliability yang terdapat pada masingmasing variabel yang besarnya $>0,7$ menunjukkan bahwa keempat variabel tersebut reliabel.

\section{b). Cronbach's Alpha}

Setelah melakukan Uji reliabilitas dengan Composite Reliability di atas kita dapat diperkuat reliabel sebuah indikator dengan mengetahui nilai nilai Cronbach's Alpha. Apabila suat variabel memiliki nilai Cronbach Alpha > 0,7 maka variabel dapat dikatakan reliabel. Berikut ini adalah nilai Cronbach's Alpha dari masing-masing variabel.

\section{Gambar 3}

\section{Cronbach's Alpha}

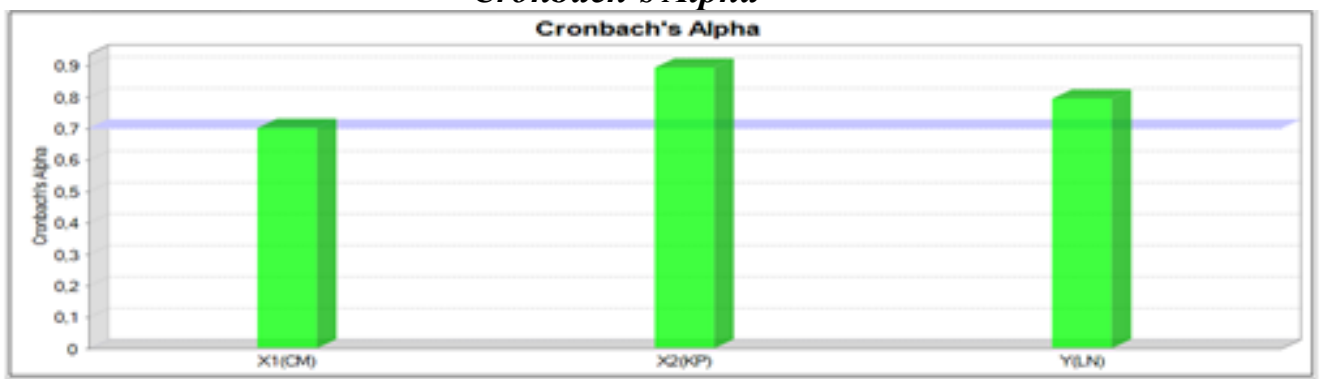

Tabel 4

Cronbach's Alpha

\begin{tabular}{lcc}
\hline $\begin{array}{l}\text { Construct Reliability } \\
\text { and Validity }\end{array}$ & Cronbach's Alpha & Keterangan \\
\hline CITRA MEREK & 0,701 & Reliable \\
KUALITAS PELAYANAN & 0,893 & Reliable \\
LOYALITAS NASABAH & 0,794 & Reliable \\
\hline
\end{tabular}

Sumber: data primer diolah, 2021

Meninjau tabel di atas hasil dari Cronbach's Alpha variabel citra merek > 0,7 yaitu sebesar 0,701 , kualitas pelayanan $>0,7$ yaitu sebesar 0,893, dan loyalitas nasabah > 0,7 yaitu sebesar 0,794. Berdasarkan hal tersebut penulis meyimpilkan bahwa hasil ini dapat menunjukkan bahwasanya tiap-tiap 
variabel penelitian telah sejalan dengan persyaratan nilai Cronbach's Alpha, sehingga dapat disimpulkan bahwa keseluruhan variabel memiliki tingkat reliabilitas yang sesuai standart yang ditentikan para ahli.

\section{2) Evaluasi Inner Model}

Pada penelitian ini akan dijelaskan mengenai hasil uji path coefficient dan uji hipotesis.

\section{a) Uji Path Coefficient}

Untuk mengetahui seberapa kuat efek atau pengaruh variabel independen kepada variabel dependen kita dapat melakukan evaluasi path coefficient. Sedangkan untuk mengukur, seberapa banyak variabel endogen dipengaruhi oleh variabel lainnya dapat pula menggunakan evaluasi coefficient determination $\quad(R$-Square). "Chin menyebutkan hasil R2 sebesar 0,67 ke atas untuk variabel laten endogen dalam model struktural, mengindikasikan pengaruh variabel eksogen (yang mempengaruhi) terhadap variabel endogen (yang dipengaruhi) termasuk dalam kategori baik. Sedangkan jika hasilnya sebesar 0,33 - 0,67 maka termasuk dalam kategori sedang, dan jika hasilnya sebesar 0,19 - 0,33 maka termasuk dalam kategori lemah". (Imam Ghozali, 2014).

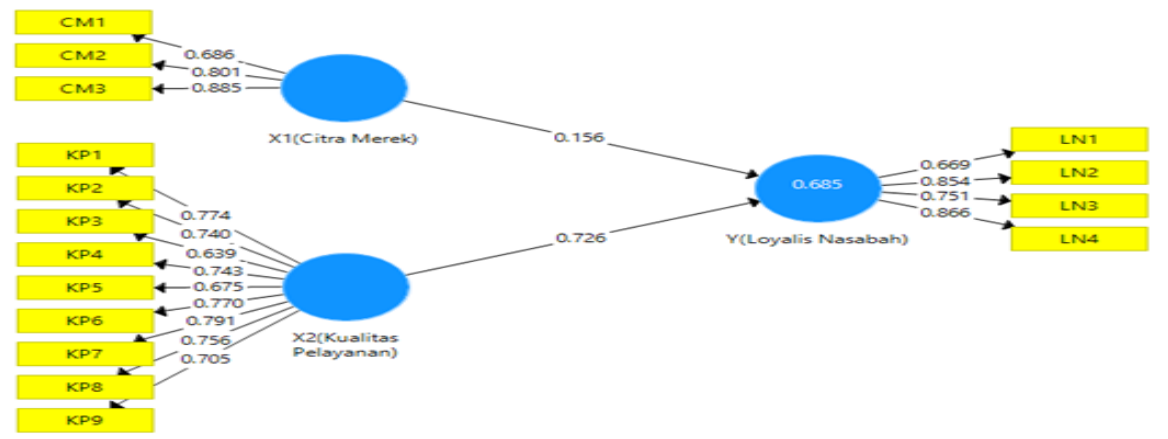

Meninjau skema inner model yang telah ditampilkan pada skema di atas, penulis menarik kesimpulan bahwa nilai path coefficient terbesar ditunjukkan dengan pengaruh kualitas pelayanan terhadap loyalitas nasabah sebesar 0,726 ,dan pengaruh yang ditunjukkan oleh citra merek terhadap loyalitas nasabah sebesar 0,156

Mengingat ouput dari pengolahan data, itu menunjukkan bahwa semua faktor dalam skema penelitian ini memiliki nilai path coefficient dengan yang angka positif. Hal ini menunjukkan bahwa semakin menonjol path coefficient pada satu variabel otonom terhadap variabel terikat, semakin meningkat pengaruh antara faktor bebas terhadap variabel terikat.

Meninjau pengolahan data yang telah dilakukan oleh penulis menggunakan Smart PLS, diperoleh nilai $R$ Square sebagai berikut:
Tabel 5 R Square

\begin{tabular}{lll}
\hline $\begin{array}{l}\text { Nilai } \boldsymbol{R} \text {-Square } \\
\text { Variabel }\end{array}$ & $\begin{array}{l}\text { Nilai } \\
\text { Square }\end{array}$ \\
\hline Loyalitas Nasabah & 0,685 \\
\hline
\end{tabular}

Sumber: data primer diolah, 2021

Meninjau hasil olah data pada tabel diatas, dapat diketahui nilai $R$ Square untuk variabel Loyalitas Nasabah adalah sebesar 0,685. Berdasarkan perolehan nilai tersebut peneliti menarik kesimpulan berdasarkan teori Imam Ghazali bahwa presentase besarnya Loyalitas Nasabah dapat dijelaskan oleh citra merek dan kualitas pelayanan sebesar $68 \%$ dan sisanya $32 \%$ dijelaskan oleh variabel lain diluar penelitian ini. 


\section{b) Uji Hipotesis}

Hasil dapat digunakan untuk menjawab hipotesis pada penelitian ini berdasarkan olah data yang telah dilakukan, dengan melihat dan mengevaluasi nilai $T$-Statistics dan nilai $P$ Values kita dapat menyimpulkan gambaran uji hipotesis pada penelitian ini. Hipotesis penelitian dapat dinyatakan diterima apabila nilai $P$-Values $<0,05$. Berikut ini adalah hasil uji hipotesis yang diperoleh dalam penelitian ini:

Tabel 6

Nilai Inner Weights

\begin{tabular}{|c|c|c|c|c|c|c|c|c|}
\hline $\begin{array}{c}\text { Path } \\
\text { Coefficie } \\
\text { nts }\end{array}$ & $\begin{array}{c}\text { Origin } \\
\text { al } \\
\text { Sample }\end{array}$ & $\begin{array}{c}\text { Samp } \\
\text { le } \\
\text { Mean }\end{array}$ & $\begin{array}{c}\text { Sta } \\
n d a \\
r \\
\text { Dev } \\
\text { iasi }\end{array}$ & $\begin{array}{c}t \\
\text { Statisti } \\
c s \\
(T s)\end{array}$ & $\begin{array}{c}t \\
\text { tabe } \\
l \\
(T t)\end{array}$ & $\begin{array}{c}P \\
\text { Value } \\
s\end{array}$ & Hasil & $\begin{array}{c}\text { Keteran } \\
\text { gan }\end{array}$ \\
\hline $\begin{array}{l}\mathrm{CM} \rightarrow \mathrm{L} \\
\mathrm{N}\end{array}$ & $\begin{array}{l}0,15 \\
6\end{array}$ & 0,156 & $\begin{array}{l}0,07 \\
4\end{array}$ & $\begin{array}{l}2,09 \\
5\end{array}$ & $\begin{array}{l}1,96 \\
0\end{array}$ & 0,000 & $\begin{array}{l}\text { Ts> } \\
\mathrm{Tt}\end{array}$ & $\begin{array}{l}\text { Positif } \\
\text { Signifik } \\
\text { an }\end{array}$ \\
\hline $\mathrm{KP} \rightarrow \mathrm{LN}$ & $\begin{array}{l}0,72 \\
6\end{array}$ & 0,736 & $\begin{array}{l}0,06 \\
4\end{array}$ & $\begin{array}{l}11,3 \\
92\end{array}$ & $\begin{array}{l}1,96 \\
0\end{array}$ & 0,249 & $\begin{array}{l}\mathrm{Ts}> \\
\mathrm{Tt}\end{array}$ & $\begin{array}{l}\text { Positif } \\
\text { Signifik } \\
\text { an }\end{array}$ \\
\hline
\end{tabular}

Berdasarkan sajian data pada tabel 6 di atas, dapat diketahui bahwa Kualitas Pelayanan (X2) memiliki nilai Pvalue sebesar 0,000 < alpha $(0,05)$ dan memiliki $\mathrm{T}$ statistik lebih besar dari $\mathrm{T}$ tabel yang artinya Kualitas Pelayanan (X2) memiliki pengaruh positif yang signifikan terhadap Loyalitas nasabah (Y). Untuk variabel Citra Merek (X1)2. memiliki nilai Pvalue sebesar 0,037 < alpha $(0,05)$ dan memiliki $\mathrm{T}$ statistik lebih besar dari $\mathrm{T}$ tabel yang artinya Citra Merek (X1) memiliki pengaruh Positif yang signifikan terhadap Loyalitas Nasabah (Y).

\section{KESIMPULAN}

Meninjau hasil penjabaran yang sudah penulis uiraikan diatas, penulis menarik kesimpulan dari hasil penelitian ini sebagai3. berikut:

1. Citra Merek $\left(\mathrm{X}_{1}\right)$ berpengaruh positif \& signifikan terhadap Loyalitas Nasabah (Y) survei pada nasabah yang melakukan transaksi menggunakan agen Brilink Bri Kantor Cabang Kemayoran. Berdasarkan hal tersebut dapat pula disimpulkan bahwa semakin tinggi Citra Merek agen Brilink Bri Kantor Cabang Kemayoran maka akan mempengaruhi Loyalitas Nasabah.

Kualitas Pelanggan $\left(\mathrm{X}_{2}\right)$ berpengaruh positif \& signifikan terhadap Loyalitas Nasabah $(\mathrm{Y})$ survei pada nasabah yang melakukan transaksi menggunakan agen Brilink Bri Kantor Cabang Kemayoran. Berdasarkan hal tersebut dapat pula disimpulkan bahwa semakin tinggi Kualitas Pelayanan yang diberikan agen Brilink Bri Kantor Cabang Kemayoran maka akan mempengaruhi Loyalitas Nasabah.

Variabel lain yang belum diteliti didalam penelitian ini harus diperhatikan oleh agen Brilink Bri Kantor Cabang Kemayoran, sebab masih banyak variable lain yang dapat 
mempengaruhi Loyalitas Nasabah dalam memilih bertansaksi pada agen Brilink agar visi dan misi Bri Kantor Cabang Kemayoran dapat tercapai.

\section{SARAN}

Hasil Penelitian ini dapat menjadi pertimbangan pihak Bri Kantor Cabang Kemayoran, berikut temuan yang dapat penulis simpulkan:

1. Berdasarkan hasil kuesioner pada variabel citra merek diperoleh jumlah persentase responden yang menyatakan "ragu-ragu" sebanyak $1,8 \%$ dan jumlah jawaban responden yang paling banyak menyatakan "ragu-ragu" dari indikator citra pembuat (corporate image). Maka untuk lebih baik lagi antara Agen Brilink dan BRI Kantor Cabang Kemayoran harus berkolaborasi atau kerjasama dengan para pakar marketing/ marketing consultan untuk lebih membangun corporate image.

2. Pihak Agen Brilink BRI Kantor Cabang Kemayoran harus lebih meningkatkan kebijakan kualitas pelayanan dikarenakan jumlah persentase jawaban responden yang menyatakan "ragu-ragu" sebanyak $4,1 \%$ dan jumlah jawaban responden yang paling banyak menyatakan "ragu-ragu" dari indikator tanggapan (responsiveness). Maka untuk lebih baik lagi Agen Brilink dan BRI Kantor Cabang Kemayoran harus berkolaborasi atau kerjasama untuk mampu menyelesaikan keluhan nasabah dengan cepat dan tanggap, agar nasabah percaya untuk transaksi di Agen Brilink.

3. Berdasarkan hasil kuesioner pada variabel loyalitas nasabah diperoleh jumlah persentase responden yang menyatakan "ragu-ragu" sebanyak $1,5 \%$ dari 4 pernyataan indikator variabel ini yang banyak menyatakan keraguanya adalah indikator pembelian secara teratur. Maka untuk lebih baik lagi antara Agen Brilink dan BRI Kantor Cabang Kemayoran harus berkolaborasi atau kerjasama untuk lebih mengenalkan Agen
Brilink dan memberikan kenyamanan serta keamanan, agar nasabah tetap loyal dan tidak terpengaruh menggunakan jasa perbankan selain Agen Brilink.

\section{DAFTAR PUSTAKA}

Ghozali I. (2008). Structural equation modeling metode alternatif dengan partial least square. (2nded). Semarang: Badan Penerbit Universitas Diponegoro.

Haryoko, U. B., Pasaribu, V. L. D., \& Ardiyansyah, A. (2020). PENGARUH HARGA DAN KUALITAS PELAYANAN TERHADAP KEPUASAN KONSUMEN PADA FIRMAN DEKORASI (WEDDING ORGANIZER). POINT: Jurnal Ekonomi Dan Manajemen, 2(1).

Kotler, Philip dan Gary Amstrong. 2014. Principles of Marketing, 12th Edition, Jilid 1 Terjemahan Bob Sabran. Jakarta: Erlangga. Kotler, Philip dan Gary Amstrong. 2012. Prinsip-prinsip Pemasaran. Edisi 13. Jilid 1. Jakarta: Erlangga.

Mauludin, Hanif. 2013. Marketing Research: Panduan Bagi Manajer, Pimpinan

Perusahaan Organisasi. Jakarta: Elex Media Komputindo.

Pasaribu, V. L. D. (2020). ANALISIS PENGARUH PROMOSI, KUALITAS PRODUK DAN DESAIN KEMASAN TERHADAP KEPUTUSAN PEMBELIAN HAND AND BODY LOTION MEREK CITRA (Studi Kasus Carrefour Pamulang, Tangerang Selatan). Jurnal Pemasaran Kompetitif, 1(4).

Pasaribu, V. L. D., \& Prayoga, M. Y. S. (2019). Pengaruh Kualitas Produk Baju Batik Hem Terhadap Kepuasan Pelanggan Pada Home 
Industri Batik Sahara Indah. Jurnal Pemasaran Kompetitif, 2(2), 77-83.

Pasaribu, V. L. D. PENGARUH STORE ATMOSPHERE TERHADAP KEPUTUSAN PEMBELIAN PADA RESTORAN DE'COST GIANT PAMULANG SQUARE TANGERANG SELATAN. Manajerial: Jurnal Manajemen dan Sistem Informasi, 19(2), 156-167.

Pasaribu, V. L. D. P. D. (2018). PENGARUH BIAYA PROMOSI TERHADAP PENINGKATAN PENJUALAN KARTU FLEXI PT. TELEKOMUNIKASI SELULER (TELKOMSEL) JAKARTA (Studi kasus Produk Kartu Flexi Pt. Telkomsel. Jakarta Selatan). Jurnal Pemasaran Kompetitif, 1(2).

PASARIBU, V. L. D. (2017). ANALISIS PENGARUH PROMOSI, KUALITAS PRODUK DAN DESAIN KEMASAN TERHADAP PERSEPSI MEREK YANG BERDAMPAK KEPADA KEPUTUSAN PEMBELIAN HAND AND BODY LOTION MEREK VASELINE (Studi Kasus TIP TOP Ciputat, Tangerang Selatan). Inovasi, 4(2).

Pasaribu, V. L. D., Septiani, F., Rahayu, S., Lismiatun, L., Arief, M., Juanda, A., ... \& Rahim, R. (2021). Forecast Analysis of Gross Regional Domestic Product based on the Linear Regression Algorithm Technique.

Qurbani, D., \& Pasaribu, V. L. D. (2019). Pengaruh Brand Image Dan Brand Trust Terhadap Brand Loyalty Nasabah Prudential Syariah Pada PT. Futuristik Artha Gemilang (Studi kasus di kantor cabang agensi Prudential Syariah PT. Futuristik Artha Gemilang Jakarta Selatan). Jurnal Pemasaran Kompetitif, 2(3), 121-135.

Putri, Yulia Larasati dan Hardi Utomo. 2017. Pengaruh Kualitas Pelayanan Terhadap Loyalitas Pelanggan Dengan Kepuasan Sebagai Variabel Intervening (Studi persepsi pada pelanggan Dian Comp
Ambara. Jurnal Among Makarti. Vol. 10, No. 19

Susendra, Indra. 2018. Analisa Pengaruh Layanan Agen Brilink BRI Terhadap Kepuasan dan Loyalitas Nasabah Pada PT Bank Rakyat Indonesia (PERSERO) Tbk Kantor Cabang Bandung Setiabudi. Tesis. Manajemen, STIE WIDYA WIWAHA, Yogyakarta.

Sangadji, Etta Mamang dan Sopiah. 2013. Perilaku Konsumen. Yogyakarta: Andi. 129 Clow, K. E. \& Baack, Donald. 2018. Integrated Advertising, Promotion, and Marketing Communications. Harlow: Pearson Education Limited.

Tilova, N., \& Rismanti, V. A. (2020). Pengaruh Persepsi Milenials tentang Gaya Kepemimpinan yang dialami di Tempat Kerja terhadap Etika Kerja Pegawai. Jurnal Mandiri: Ilmu Pengetahuan, Seni, Dan Teknologi, 4(2), 139-149.

Tilova, N. (2019). Meninjau Kinerja Guru Islam: Adversity Quotient dan Spiritual Quotient. SCIENTIFIC JOURNAL OF REFLECTION: Economic, Accounting, Management and Business, 2(2), 211220.

Tilova, N., \& Anismadiyah, V. (2020). PENGARUH IKLIM ORGANISASI DAN BEBAN KERJA TERHADAP PRESTASI KERJA DOSEN. KREATIF: Jurnal Ilmiah Prodi Manajemen Universitas Pamulang, 8(2), 1-14.

Tjiptono, Fandy. 2012. Strategi Pemasaran. Edisi 3. Yogyakarta: Andi. 